Meta

Journal des traducteurs

Translators' Journal

\title{
Ministère italien de la culture, Cahiers de la traduction
}

\section{Fabrizio Megale}

Volume 41, numéro 1, mars 1996

Le(s) processus de traduction / Translation Process(es)

URI : https://id.erudit.org/iderudit/003535ar

DOI : https://doi.org/10.7202/003535ar

Aller au sommaire du numéro

\section{Éditeur(s)}

Les Presses de l'Université de Montréal

ISSN

0026-0452 (imprimé)

1492-1421 (numérique)

Découvrir la revue

Citer ce compte rendu

Megale, F. (1996). Compte rendu de [Ministère italien de la culture, Cahiers de la traduction]. Meta, 41(1), 181-182. https://doi.org/10.7202/003535ar

Ce document est protégé par la loi sur le droit d'auteur. L'utilisation des services d'Érudit (y compris la reproduction) est assujettie à sa politique d'utilisation que vous pouvez consulter en ligne.

https://apropos.erudit.org/fr/usagers/politique-dutilisation/
Cet article est diffusé et préservé par Érudit.

Érudit est un consortium interuniversitaire sans but lucratif composé de l’Université de Montréal, l'Université Laval et l'Université du Québec à Montréal. Il a pour mission la promotion et la valorisation de la recherche. https://www.erudit.org/fr/ 
Ministère italien de la culture, Cahiers de la traduction.

Depuis 1992, le Ministère italien de la culture consacre périodiquement un numéro spécial de sa revue Libri e Riviste d'Italia à la traduction, tant du point de vue théorique que professionnel. C'est là un des résultats les plus importants du «Centre pour les traducteurs» fonctionnant auprès du Ministère, qui va de pair avec l'autre grande initiative en la matière : l'institution des Prix nationaux de la traduction. Le Centre s'occupe aussi de recueillir, conserver et diffuser au niveau national toute information et documentation concernant la profession de traducteur (recherches, articles, répertoires, bibliographies, etc.). 
Jusqu'à ce jour, deux numéros spéciaux de Libri e Riviste d'Italia ont été publiés, sous la direction du Prof. Enrico Arcaini. Dans chacun d'eux, la première partie contient des articles de théorie de la traduction, tandis que la deuxième est consacrée à la profession de traducteur, sous la forme d'articles informatifs normalement suivis par de la documentation (extraits de lois, jurisprudence, contrats, statistiques, enquêtes, etc.).

Le premier numéro (Supplément au no 514 de septembre 1992) est dédié, dans sa partie théorique, aux différentes formes de traduction (juridique, scientifique, poétique, philosophique, etc.) et, dans sa partie pratique, à la profession de traducteur littéraire et technique en Italie. La documentation enclut, notamment, la loi sur le droit d'auteur, des exemples de contrats de traduction (comparés à leurs homologues français, anglais, allemands et espagnols, également publiés), un aperçu sur les traducteurs dans la fonction publique et dans les cours de justice ainsi que des statistiques sur la traduction de livres.

Le deuxième numéro (no 538 de septembre 1994) contient une première partie sur la traduction au Brésil, notamment dans ses rapports avec la littérature italienne, et une deuxième partie consacrée à la profession de traducteur pour le cinéma et la télévision en Italie. Les articles de cette dernière partie analysent en particulier l'activité de traduction des dialogues de films, le statut juridique et fiscal, la situation de marché et les cours de formation disponibles alors que la documentation comprend le droit d'auteur applicable, la jurisprudence, les contrats en usage et une longue bibliographie.

Ces deux numéros spéciaux de Libri e Riviste d'Italia peuvent être demandés à l'adresse suivante : M. Elio Silvestro, Direttore del Centro per i traduttori, Ministero dei beni culturali, Via del Collegio Romano 25, I-00186 Roma (Italie). 